\title{
Flacourtiaceae endémicas del Perú
}

\section{Blanca León ${ }^{1,2}$}

${ }^{1}$ Museo de Historia Natural, Av. Arenales 1256, Aptdo. 14-0434, Lima 14, Perú

2 Plant Resources Center, University of Texas at Austin, Austin TX 78712 EE.UU.

blanca.leon@mail.utexas.edu

\section{Resumen}

La familia Flacourtiaceae es reconocida en el Perú por presentar 19 géneros y 65 especies (Brako \& Zarucchi, 1993; Ulloa Ulloa et al., 2004), mayormente arbustos y árboles. En este trabajo reconocemos tres especies endémicas en dos géneros, las cuales ocupan la región de los Bosques Muy Húmedos Montanos, entre los 2300 y 3600 m de altitud. Solamente una de estas especies se encuentra representada en el Sistema Nacional de Áreas Naturales Protegidas por el Estado.

Palabras claves: Flacourtiaceae, Perú, endemismo, plantas endémicas.

\section{Abstract}

The Flacourtiaceae are represented in Peru by 19 genera and 65 species (Brako \& Zarucchi, 1993; Ulloa Ulloa et al., 2004), mainly shrubs and trees. Here we recognize three endemic species in two genera, which are found in the Very Humid Montane Forests region, between 2300 and $3600 \mathrm{~m}$ elevation. One endemic Flacourtiaceae species has been registered within Peru's protected areas system.

Keywords: Flacourtiaceae, Peru, endemism, endemic plants.

\section{Abatia rugosa Ruiz \& Pav.}

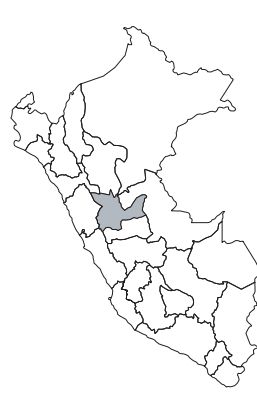

\section{DD}

Publicación: Fl. Peruv. Prodr. 78, pl. 14. 1794.

Colección tipo: H. Ruiz \& J. Pavón s.n. Herbarios: MA.

Nombre común: Galgaretama, retama cimarrona, taucca taucca, tauhac tauhac, yoriturpi.

Registro departamental: HU. Regiones Ecológicas: BMHM; 2500$3000 \mathrm{~m}$.

SINANPE: Sin registro.

Herbarios peruanos: USM (3).

Observaciones: Arbusto conocido de unos pocos ejemplares en el Perú, la mayoría de ellos en la cuenca del Huallaga. Una planta de Panamá se atribuye a esta especie, pero no pudo ser verificada.

\section{Abatia spicata (Turcz.) Sleumer}

DD

Publicación: Repert. Spec. Nov. Regni Veg. 45: 13. 1938

Colección tipo: A. Mathews 1204

Herbarios: CW.

Nombre común: Escobilla.

Registro departamental: AP, CU, HV. Regiones Ecológicas: BMHM; 2300$3600 \mathrm{~m}$

SINANPE: SHMP

Herbarios peruanos: CUZ (1), USM (2).

Observaciones: Especie arbustiva, cercanamente relacionada con Abatia spicata. Esta especie ha sido recolectada en el centro y sur del país, de las cuencas del Apurímac, Mantaro y Urubamba. Requiere evaluarse su estatus taxonómico.

\section{Xylosma raimondii Sleumer}

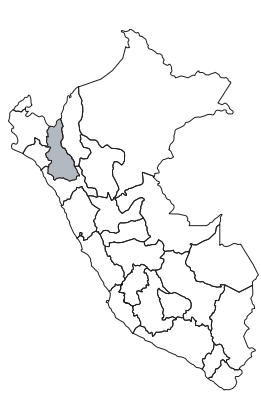

DD

Publicación: Fl. Neotrop. 22: 168. 1980. Colección tipo: C. Jelski 22

Herbarios: L, W.

Nombre común: Desconocido.

Registro departamental: CA.

Regiones Ecológicas: Sin datos; altitud desconocida.

SINANPE: Sin registro.

Herbarios peruanos: Ninguno.

Observaciones: Esta especie arbórea es conocida solamente de la colección tipo proveniente de los bosques húmedos de la Provincia de Cutervo. El ejemplar tipo fue recolectado en el siglo XIX. 